Letter

\title{
Advancing Pervious Pavements through Nomenclature, Standards, and Holistic Green Design
}

\author{
Charles E. Sprouse III * ${ }^{\mathbb{D}}$, Conrad Hoover, Olivia Obritsch and Hannah Thomazin
}

School of Engineering, Benedictine College, Atchison, KS 66002, USA; hoov1599@ravens.benedictine.edu (C.H.); obri7529@ravens.benedictine.edu (O.O.); thom0999@ravens.benedictine.edu (H.T.)

* Correspondence: csprouse@benedictine.edu; Tel.: +1-913-360-7958

Received: 3 August 2020; Accepted: 3 September 2020; Published: 9 September 2020

\begin{abstract}
Researchers developing pervious pavements over the past few decades have commendably demonstrated long-term run-off reduction using a diverse collection of materials. Today, pervious pavements are widely recognized as a low impact development technique and a type of green infrastructure, and installations are proliferating throughout the United States and worldwide. The entire field of pervious pavements though, is being profoundly stunted by three persistent problems: conflicting nomenclature, flawed testing standards, and the absence of a holistic green design framework. This study examines each problem and proposes novel solutions. On nomenclature, a multi-channeled study of the terms "pervious", "permeable", and "porous" considers each word's etymology and usage in the academic literature, in ASTM International standards, and by (U.S.-based) governmental entities. Support is found for using pervious pavements (i.e., "through" the "road") as the over-arching category of all water passable pavements, branching down into porous pavements (i.e., "full of pores", including porous asphalt and porous concrete) and permeable pavements (i.e., "containing passages", often between paver units). ASTM International standards are shown to insufficiently account for the impact of paver unit size on infiltration rate, warranting the development of a more reliable testing method featuring variable infiltration ring size, shape, and placement. Finally, a ten-part holistic green design framework is elucidated for use in assessing candidate pavements and engineering new pavements, contextualizing the latest pervious pavement research and illuminating a brighter path forward.
\end{abstract}

Keywords: pervious pavement; permeable pavement; porous pavement; pavement nomenclature; pavement standards; holistic green design

\section{Introduction}

The concept of pervious pavements (pavements "allowing passage" of water) has been around Europe for over a century-and-a-half, with porous concrete installations dating back to 1852 [1]. In the United States, the timeline spans closer to a half-century, with The Franklin Institute Research Laboratories beginning to study porous pavements in 1968, and a collaboration with the U.S. Environmental Protection Agency (EPA) producing the first official guide for pervious pavement in 1978, titled Porous Pavement and authored by Thelen and Howe [2]. For further details of the early history of the technology in the U.S., the interested reader may consult Appendix II of the guide [2].

Critical groundwork for today's resurgent interest in pervious pavements was laid by the formation of the U.S. Green Building Council (USGBC) in 1993, and its Leadership in Energy and Environmental Design (LEED) building rating system v1.0 in 1998 [3]. Over the past two decades, LEED has been a main catalyst for increased research and adoption of pervious pavements in the U.S., raising awareness of the potential environmental, social, and economic benefits of including green design features [4]. As research has progressed, LEED rating systems (from v1.0 in 1998 to v4.1 in 2019) have been refined 
to better measure the overall eco-friendliness of designs. For example, the initial scoring system (v1.0) simply tallied the number of green features in a design [4], whereas LEED v2009 (v3) incorporated weightings for credits, with more environmentally beneficial credits earning more points [5].

Despite LEED's initial focus on buildings, the ratings systems quickly expanded to include areas outside buildings (and even transportation to/from buildings). Because pervious pavements permit stormwater passage and preserve local hydrology, pervious pavements are recognized as a Low Impact Development (LID) technique for rainwater management by LEED [6] and a type of green infrastructure by the U.S. Environmental Protection Agency (EPA) [7]. In the U.S., Section 438 of the Energy Independence and Security Act (EISA) of 2007 requires federal projects greater than 5000 square feet (464.5 square meters) to reduce stormwater runoff to pre-development conditions [8]. Federal agencies can comply via a variety of green infrastructure practices, including the use of pervious pavements [9].

As enumerated by Ashley in Table 1, pervious concrete was eligible for several LEED v2009 credits, recognizing its potential to reduce and clean stormwater, reflect sunlight, store water for landscaping, and use recycled and local materials [10].

Table 1. Leadership in Energy and Environmental Design (LEED) v2009 Credits Available to Installations of Pervious Concrete (adapted from [10]).

\begin{tabular}{|c|c|}
\hline LEED v2009 Credit & Simplified Description \\
\hline $\begin{array}{l}\text { Sustainable Sites: SS-C6.1 } \\
\text { Stormwater Design-Quantity Control }\end{array}$ & $\begin{array}{l}\text { Credit for limiting stormwater runoff (for primarily } \\
\text { impervious areas, reduce stormwater runoff by } \geq 25 \% \\
\text { from the two-yr, 24-hr design storm). }\end{array}$ \\
\hline $\begin{array}{l}\text { Sustainable Sites: SS-C6.2 } \\
\text { Stormwater Design-Quality Control }\end{array}$ & $\begin{array}{l}\text { Credit for filtering post-development total suspended } \\
\text { solids (treats } \geq 90 \% \text { of rainfall and removes } \geq 80 \% \text { of } \\
\text { solids). }\end{array}$ \\
\hline $\begin{array}{l}\text { Sustainable Sites: SS-C7.1 } \\
\text { Heat Island Effect-Non-Roof }\end{array}$ & $\begin{array}{c}\text { Credit for shading, unbounded loose substrates, } \\
\text { or materials reflecting incident sunlight (Solar } \\
\text { Reflectance Index (SIR) } \geq 29 \text { ). }\end{array}$ \\
\hline $\begin{array}{l}\text { Water Efficiency: WE-C1.1 } \\
\text { Water Efficient Landscaping }\end{array}$ & $\begin{array}{l}\text { Credit for reducing landscaping water usage by } \\
\text { storing and using stormwater ( } \geq 50 \% \text { reduction by } \\
\text { using water from pervious concrete sub-base). }\end{array}$ \\
\hline $\begin{array}{c}\text { Materials and Resources: MR-C4.1, MR-C4.2 } \\
\text { Recycled Content }\end{array}$ & $\begin{array}{l}\text { Credit for using materials with recycled content } \\
\text { (postconsumer }+ \text { one-half preconsumer } \geq 10 \% \text { for one } \\
\text { point, } \geq 20 \% \text { for two points-by cost). }\end{array}$ \\
\hline $\begin{array}{c}\text { Materials and Resources: MR-C5.1, MR-C5.2 } \\
\text { Regional Materials }\end{array}$ & $\begin{array}{l}\text { Credit for using materials sourced within } \leq 500 \mathrm{mi} \\
(805 \mathrm{~km}) \text { radius ( } \geq 10 \% \text { for one point, } \geq 20 \% \text { for two } \\
\text { points-by cost). }\end{array}$ \\
\hline
\end{tabular}

Each credit listed in Table 1 is still included in the current LEED rating system, v4.1 [11]. Importantly, as LEED systems have grown in complexity (including 21 ratings systems adaptations), usage of LEED has expanded to Canada and across the world. Going forward, LEED remains a catalyst for the adoption of pervious pavements, holding increasing global influence.

For researchers, LEED's scientific metrics offer reference points for initial and ongoing design performance. Furthermore, LEED credits represent areas of competition between different pavement types, since the same credit (e.g., use of recycled materials) can be achieved with numerous types of sustainable pavements. The mechanisms by which pervious pavements earn stormwater and water efficiency credits are represented in Figure 1, where contrasts are drawn with traditional pavements. In urbanized areas, water run-off from roadways and walkways is traditionally drained into storm drains and channels. Once captured, the run-off either flows to reclamation centers for filtration, spills into creeks or rivers, or dumps into settling ponds. In all these cases, run-off water is not treated immediately and often carries roadside pollutants such as oils, heavy metals, and other undesirable 
debris to the water's end destination, arriving untreated. Pervious pavements handle rainwater (and entrained pollutants) by bringing water treatment to the pavement itself, eliminating the need for run-off after-treatment and potentially eliminating the need for stormwater drainage networks entirely. In this context, water treatment entails reducing the amount of contaminants (e.g., oils, metals, particulates) flowing out of the pavement (e.g., to groundwater, for irrigation), which is predominantly achieved when contaminants become trapped between sand particles and the boundaries of the pavement voids in which they reside [12]. Due to the microscopic size and low concentration of contaminants, the hydraulic and sequestration performance of most pervious pavements are insensitive to contaminant buildup.

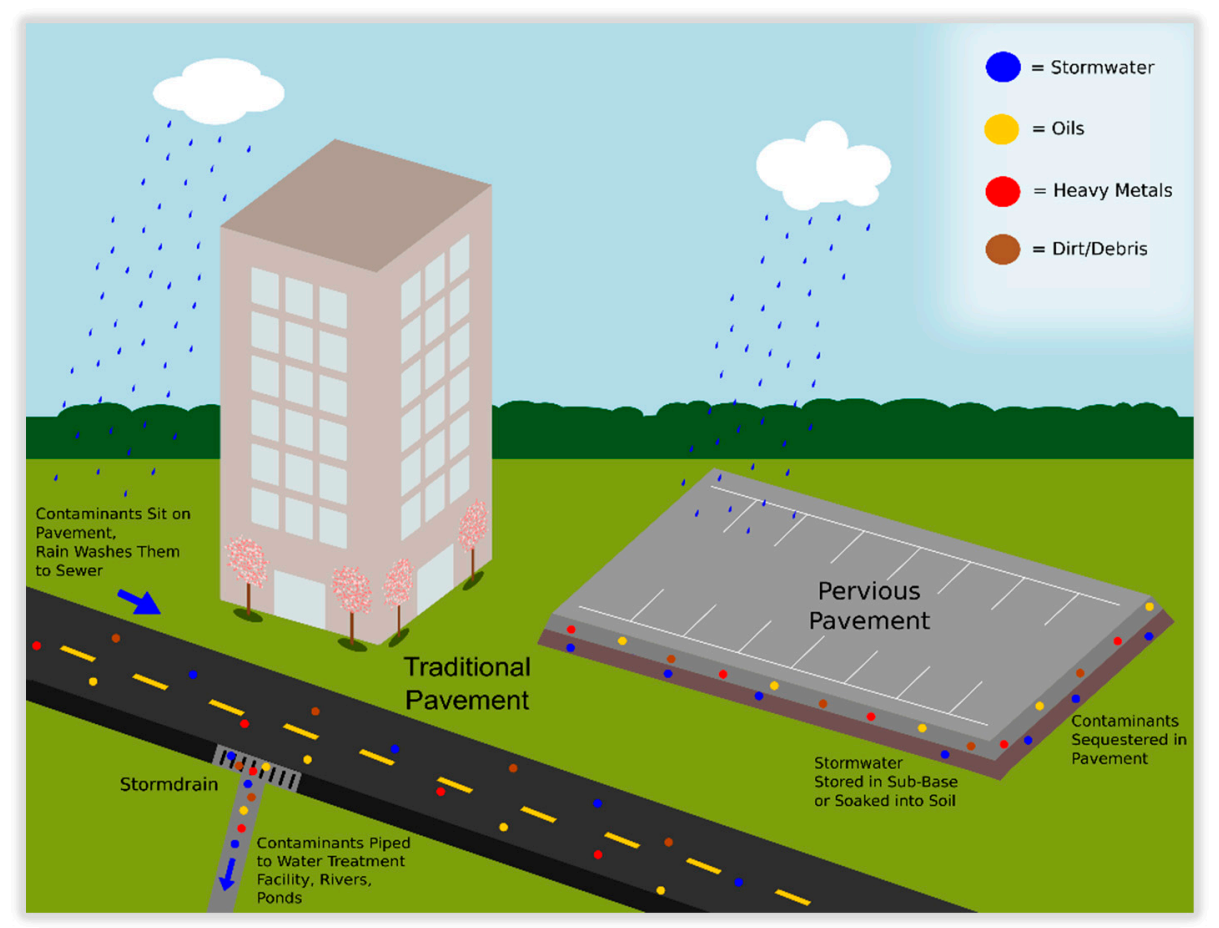

Figure 1. Contrasting stormwater and pollutant treatments between traditional and pervious pavements, with pervious pavements bringing treatment on-site.

Aside from water-related benefits, pervious pavements can also decrease the heat island effect [13], have a lower environmental cost of production (e.g., lower embodied carbon) than traditional asphalt or concrete [14], and use significant amounts of recycled and regionally-sourced materials [15]. More fundamentally though, the choice of whether to use traditional or pervious pavements involves determining whether it is necessary to transport stormwater off site, which is influenced by the area's soil properties, surrounding structures, and space constraints. For example, heavy rainfall events and drainage-restricting (e.g., clayey) soil may place vulnerable structures at risk of elevated hydrostatic pressures. Alternatively, space-restricted cities may not have adequate surface area for stormwater drains, ditches, or green space drainage [16].

Pervious pavement materials are uniquely challenged to support travel while featuring strength-reducing passageways, passageways permitting water flow, capturing fine particulate matter particles $\left(\mathrm{PM}_{2.5}\right.$, having particle diameters $\left.<2.5 \mu \mathrm{m}\right)$, and limiting plugging from dirt and debris. Pavement developers have taken many parallel paths towards meeting these challenges, often involving the categories represented in Figure 2. Porous asphalt and porous concrete contain openings in their surface and throughout their depth, allowing water passage and supporting traffic in a near-homogeneous manner (although some installations have larger aggregate borders framing the pavement to handle heavy rainfall events). Concrete Grid Pavers (CGPs) have an open-grid with substantial room for in-fill (usually either dirt, sand, or rock), where most of the water passes through. 
Permeable Interlocking Concrete Pavers (PICPs) have more of a closed grid, with less room for infill, though again the joints permit most of the water flow. Plastic reinforcement grids are highly open (usually $\geq 90 \%$ ), with a plastic grid providing strength and the infill allowing water passage. Finally, natural rock pavers have non-standardized shapes with water flowing infill.

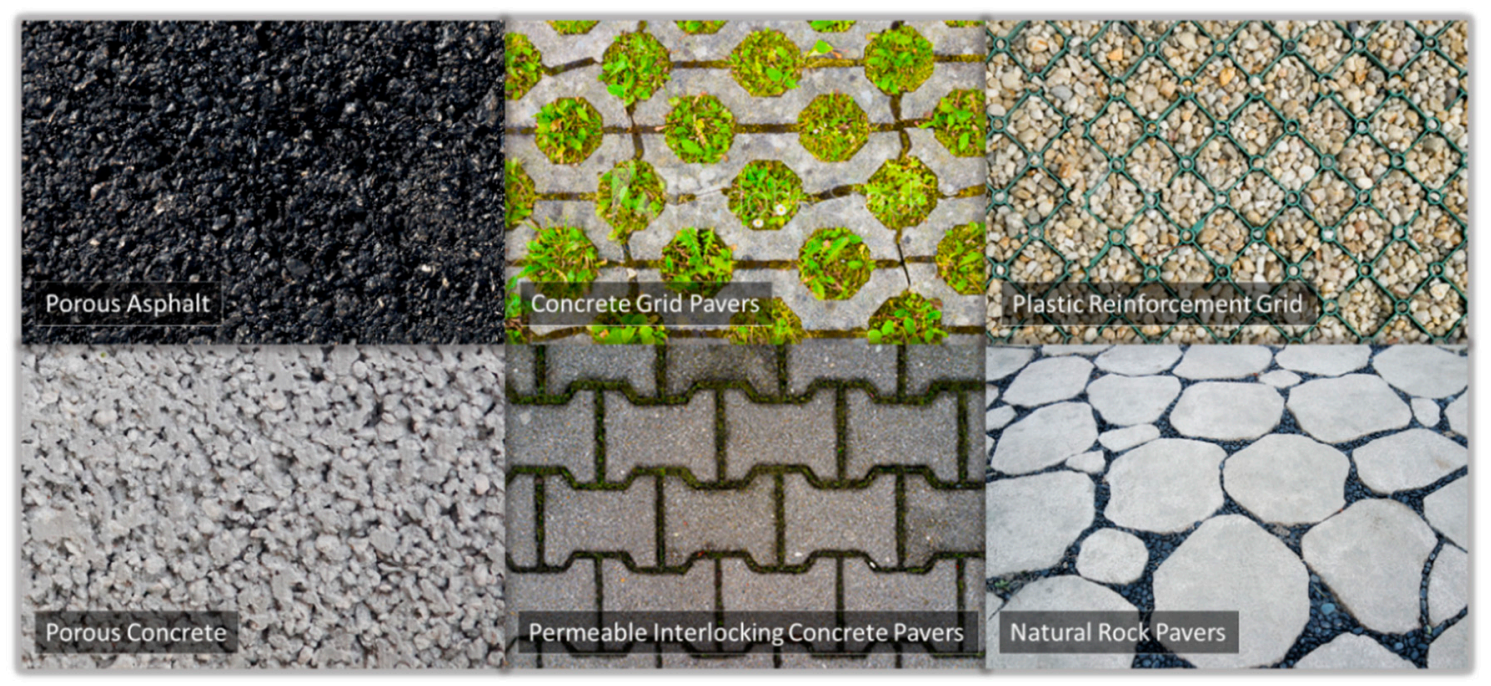

Figure 2. Six common pervious pavements: porous asphalt, concrete grid pavers, plastic reinforcement grid, porous concrete, permeable interlocking concrete pavers, and natural rock pavers.

The aim of the present study is to assist academicians in further advancing pervious pavements using three avenues: offering consistent nomenclature for improved cooperation (Section 3.1), suggesting improvements to standards for enhanced testing reliability (Section 3.2), and elucidating a framework for holistic green design that reveals interconnections and research opportunities (Section 3.3). Motivation for the study comes from numerous authors in the literature lamenting the inconsistent usage of the adjectives pervious, porous, and permeable as modifiers for pavements [17,18], and documented discrepancies in Surface Infiltration Rate (SIR) testing results using current standards $[19,20]$. The impetus behind the holistic framework is in one sense basic, since sustainable pavements applications have complex needs that are not thoroughly outlined elsewhere; however, it is in another sense esoteric, since the framework represents a singular vision greater than the sum of its individual parts. Ultimately, this study advances the field of pervious pavements along all three avenues and merits contemplation by everyone interested in fostering pervious pavement innovation and success.

\section{Materials and Methods}

The nomenclature study's scope includes any pavement that allows significant direct-through water passage, either with a continuous surface (e.g., porous asphalt) or discontinuous surface (e.g., pavers with flow-permitting infill). A diverse collection of linguistic data is gathered by considering each term's etymology and modern usages in various contexts: academic literature, LEED ratings systems, ASTM International standards, and (U.S.-based) governmental entities (e.g., EPA). Efforts are made to consider international influences, with the notable exception of limiting the study of governmental documents to the United States due to the impracticality of reviewing policy guidelines throughout the world. Consequently, the linguistic study is valuable to all investigators, especially when viewed in combination with each investigator's government's language. Methodologically, a critical examination and analysis of the linguistic data directly leads to the development of a terminological structure for all types of water passage permitting pavements.

Regarding pervious pavement standards, ASTM International publishes the most widely used testing standards, including standards for on-site surface infiltration rate testing and paving 
unit strength testing. Furthermore, relevant standards address joint sizes, pavement thicknesses, and masonry terminology. Standards are considered collectively alongside the abundant variety of available (and foreseeable) pervious pavements, allowing assessment of the presence and sufficiency of existing standards. By comparing the physical mechanisms governing pavement performance to those present under test conditions, several opportunities are found for improving infiltration rate testing.

A decided aim of the holistic green design framework is to offer a cohesive vision for pervious pavements, not a disjointed checklist of features or goals. The goal is environmental stewardship, where designers innovate using the full resources of the world while also assuming the responsibility to care for all aspects of our immensely interconnected world. In other words, the holistic framework uniquely captures the many causes, effects, relationships, and circumstances that are present with pervious pavements.

Producing a holistic green design framework involves weaving together the fundamentals of various fields, including design [21,22], environmental engineering [23], material selection [24,25], low impact development [7], and porous pavements [12]. To give context, the framework incorporates technical environmental insights $[26,27]$ and the current circumstances of the environment and society $[28,29]$. The framework itself is the primary result of Section 3.3 , and secondary results appear as observations about the state of research. For example, the framework offers support for incorporating more natural/biological materials and developing generalized analytical models featuring controllable parameters (e.g., joint width) across the multitude of pavement compositions, patterns and structures, and manufacturing processes in the literature $[30,31]$.

\section{Results}

\subsection{Resolving Terminology of Porous, Permeable, and Pervious Pavements}

As research on these types of pavements has grown, branched, and evolved, distinctions between porous, permeable, and pervious have not been thoroughly pursued. A natural effect of this ambiguity is the inconsistent and interchangeable use of terms seen in the literature, leading to inefficiencies and increasing the likelihood of mistakes by researchers, standards development organizations, policymakers, and practitioners. The most detailed consideration of the porous vs. permeable vs. pervious question is provided here, by considering the roots and uses of each word in various contexts, demonstrating trends in use (without aiming to analyze every available use of the terms) and concluding by proposing consistent terminology.

Each of the three primary terms are of Latin origin, and interestingly, detailed study of the Latin roots proves useful in making distinctions, even more so than their modern definitions. Porous comes from the Latin "porus" meaning "an opening" or "passage", Medieval Latin "porosus", and Old French "poros" meaning "full of pores" [32]. The modern definition of porous is "admitting the passage of gas or liquid through pores or interstices" [33]. Based on this linguistic information, especially the phrase "full of pores", porous refers clearly to materials with empty spaces whereby other material may enter for potential passage.

Permeable and pervious use the same Latin prefix "per" meaning "forward" or "through" [34,35]; however, permeable ends with the Latin "meare" meaning "to pass" and pervious ends with the Latin "via" meaning "road" [34,35]. Literally, pervious means "through" the "road". Etymological entries for permeable include variations of "permeablis" meaning "passable" and most interestingly "permeare" meaning "to pass through, go over" [34]. At this level of fine detail, permeable falls more closely in line with a paving system whereby water flow would occur either by passing through (e.g., an aggregate-filled joint) or flowing over (e.g., across a paving stone) before passing through (e.g., a joint). Alternatively, pervious is suitable as a general over-arching category with flow "through the road". Little additional insight comes from modern definitions, with permeable meaning "capable of being permeated or penetrated, especially by liquids or gases" and pervious meaning "open to passage or entrance; permeable" [33]. 
Shifting focus to the seminal U.S. publication Porous Pavements, the authors state "porous pavement consists of an open-graded asphalt concrete over an open-graded aggregate base, over a draining soil" (see Figure 3) [2]. While the authors' stated aim of porous pavement is to absorb runoff water as an aid against flooding and droughts, the term "porous pavements" is consistently connected with continuous surface layer materials with large numbers of sizable voids collectively comprising a high percentage of the material volume (i.e., high void fraction).

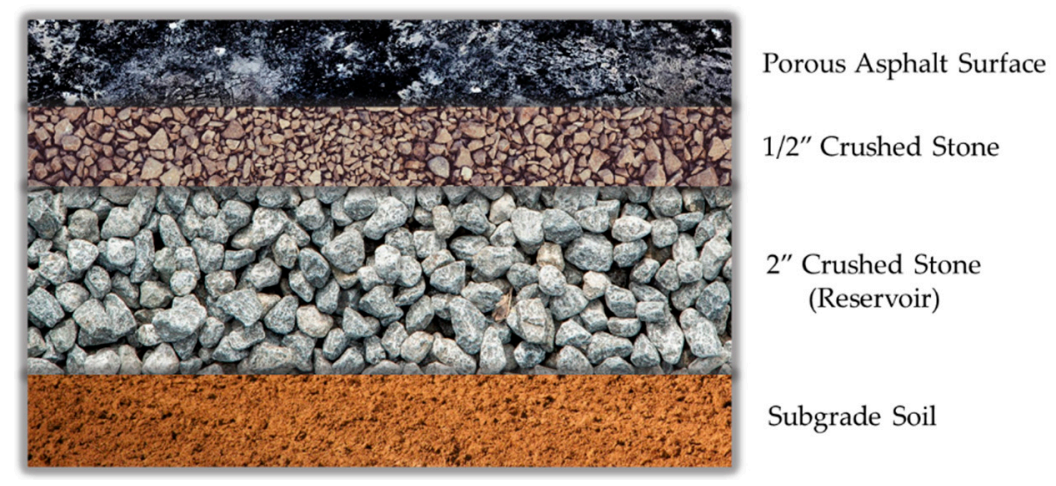

Figure 3. Porous asphalt cross-section (adapted from Thelen and Howe [2]).

Among U.S. state organizations, noteworthy reports titled Urban Waterways come from the North Carolina State University Cooperative Extension [17,36]. In [36], "permeable pavements" is used as the over-arching name for alternatives to impervious pavements and high void fraction asphalts and concretes are termed "pervious", while closed-grid concrete pavers are called "permeable interlocking concrete pavers (PICPs)". The authors postulate that "porous" does not imply interconnection of void spaces (permitting the passage of water), and consider permeable and pervious to be "synonymous", while also recognizing that the three terms are used interchangeably [17]. In their area, the North Carolina Department of Environment and Natural Resources preferred the term "permeable" [17], which remains true [37].

Another notable municipal report is titled Comparison of Permeable Pavement Types: Hydrology, Design, Installation, Maintenance and Cost from the Wisconsin Department of Transportation (via CTC \& Associates LLC), which synthesizes the findings of numerous research studies and references informational resources about various pavements [38]. While terminology is not addressed directly, the authors tend to use "permeable" in an over-arching sense and choose to name specific sections "porous asphalt", "pervious concrete", and "paver blocks and permeable interlocking concrete" [38]. This type of categorization appears to be in line with the National Pollutant Discharge Elimination System (NPDES) of the U.S. EPA in 2009; however, considerable variability in nomenclature exists within the dozens of publications cited [38]. For example, the New Jersey Stormwater Best Management Practices Manual uses "pervious pavement systems" as the over-arching term for "paved areas that produce less stormwater runoff than areas paved with conventional paving", "porous paving" for porous asphalt or concrete, and "permeable pavers" for impervious concrete pavers [39]. A similar over-arching use of pervious occurs in a stormwater management tool for Duluth, MN-Lake Superior, though they use pervious for high void fraction continuous surface materials (e.g., "pervious asphalt", "pervious concrete") [40]. In sum, if generalizations are to be made in the presence of widespread terminological inconsistencies, U.S. governmental bodies tend to use: "porous asphalt" when referring to high void fraction continuous surface asphalt, either "pervious concrete" or "porous concrete" when referring to high void fraction continuous surface concrete, "permeable pavement systems" for grids of pervious or impervious pavers, and "permeable pavements" or "pervious pavements" as the over-arching term [38]. Again, exceptions are common, such as the U.S. Geological Survey's Scientific Investigations Report 2018-5037 using "permeable asphalt" and "permeable concrete" [41]. Researchers outside the U.S. are encouraged to consider the publications of their own government. 
In the foundational 2005 textbook titled Porous Pavements, Ferguson uses "porous" nearly-ubiquitously, except for "open-jointed paving blocks" and "open-celled paving grids" [12]. The book Permeable Pavements from the American Society of Civil Engineers offers yet another variation, using "permeable" as the over-arching term, with "porous" asphalt, "pervious" concrete, and "permeable" pavers [42].

Regarding the globally adopted standards of ASTM International, the foundational standard C1232-17-Standard Terminology for Masonry uses the term "permeable paving unit" and defines "permeable unit pavement system" as "pavement with wearing surface made from clay or concrete units that allows infiltration of water through open-graded aggregate in the joints, cores, or other openings, to a bed, base, and subbase, or combinations thereof" [43]. In C1781/C1781M-18-Standard Test Method for Surface Infiltration Rate of Permeable Unit Pavement Systems, unit pavement systems are again associated with "permeable", and the organization offers a clarifying note saying C1701/C1701M Test Method for Infiltration Rate of In Place Pervious Concrete should be used for "pervious concrete", a standard that is "functionally identical" except for excluding provisions associated with discontinuous surfaces $[44,45]$.

Focusing on academic works containing copious citations, Scholz and Grabowiecki's review uses "porous asphalt" and "porous concrete" (classified as "porous pavement systems") for continuous-surface pavements, and "permeable pavement systems" for discontinuous surface pavements (predominantly unit-paver-based) [30]. Alternatively, Jayasuriya and Kadurupokune extrapolate pervious pavements as a general category of pavements reducing run-off and filtering sediments, under which are porous pavements (a "thick porous layer with strong infiltration capacity") and permeable pavements ("normally constructed by impervious paver concrete blocks with infiltration voids between the blocks") [31]. In their comparative study, Chen et al. [46] acknowledge inconsistencies in pavement nomenclature and testing results, frequently citing Li [47]. Commenting on the "state of the art", Pantsi et al. [48], citing Alsubih [49], consider "pervious pavement" an over-arching term containing "porous pavement" (continuous surface) and "permeable pavement" (discontinuous surface). In their 2019 review, Xie et al. predominantly use "permeable concrete" and "pervious concrete", although "porous concrete" also appears during the discussion of other research [18].

As is overwhelmingly evident in the selective sampling of published efforts in this section, inconsistencies exist within (and across) word etymologies and published usages, leading to ineffective communication and collaboration. With careful consideration to all the usage trends and stakeholders involved, a terminological structure to alleviate these problems is offered in Figure 4.

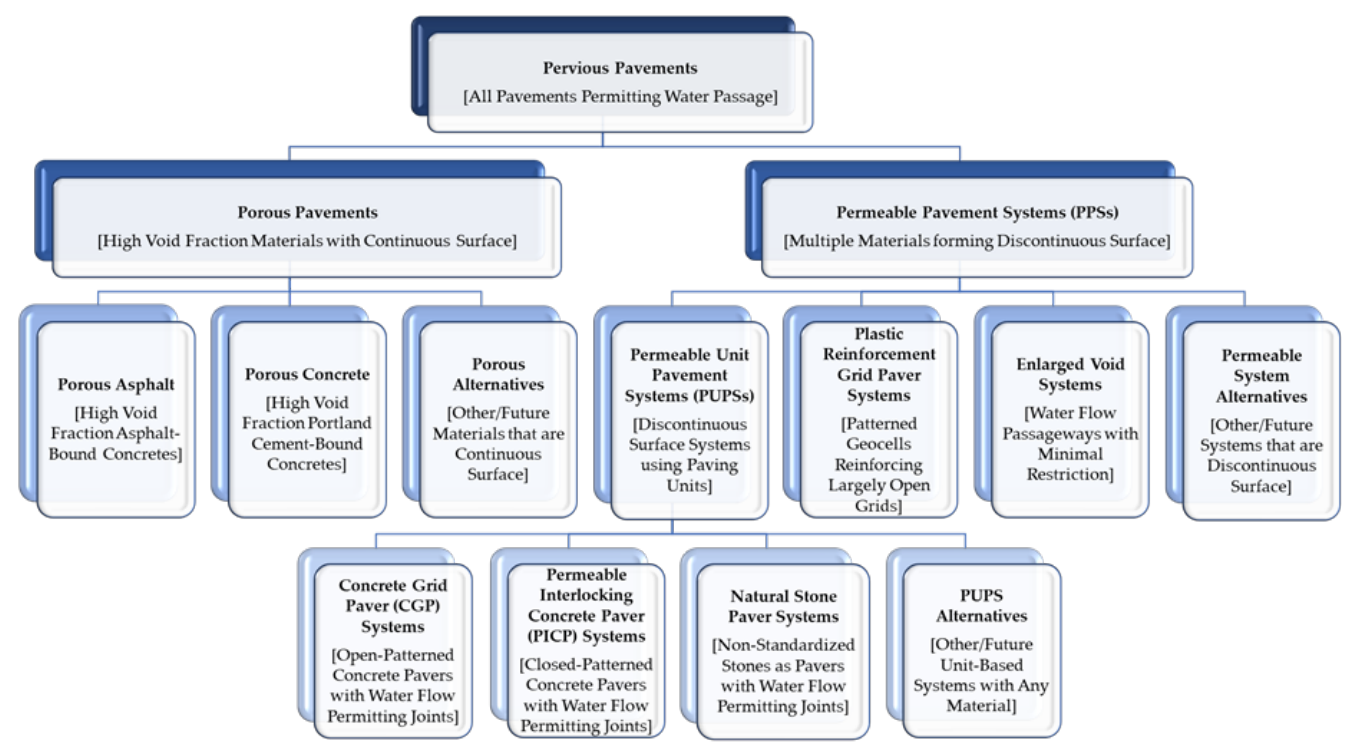

Figure 4. Terminological structure for all pavements permitting water passage. 
Structurally, "pervious pavements" is the catch-all term, as any pavement permitting water flow "through" the "road". Precedent for using pervious in the general sense can be found in the literature examples of Jayasuriya and Kadurupokune [31] and Pantsi [48], as well as governmental examples in New Jersey [39] and Duluth (Minnesota) [40]. "Porous" covers continuous surface materials with internal water passage, which is consistent with the root meaning "full of pores" and the seminal work (Porous Pavements) of Thelen and Howe [2]. Practically, porous is the most common adjective assigned to high void fraction continuous surface Portland cement-bound concrete (i.e., porous concrete) and high void fraction continuous surface asphalt-bound concrete (i.e., porous asphalt), despite ASTM International using "pervious concrete". Linguistically, casual use of "pervious concrete" is permissible under the proposed terminology; however, flow through continuous surface materials is naturally governed by "pores", as is best reflected by the proposed structure.

Permeable is the best choice for the discontinuous surface category since permeable is widely used with unit paver systems of various types, and etymologically with "permeare" meaning "to pass through, go over". By following "permeable pavement" with "systems", the complexity of discontinuous surface technologies is reflected, and the common acronyms PPSs (permeable pavement systems) and PICPs (permeable interlocking concrete paver systems) are maintained. Permeable Unit Paver System (PUPS) is a term used by ASTM International in C1232-17, though in Figure 4. PUPSs allows for the pavers themselves to be porous (revisited in Section 3.2). For further clarity, examples of PUPSs are Concrete Grid Pavers (CGPs) (a term used by ASTM International in C1319) with sizable built-in open spaces, such as Turftone ${ }^{\mathrm{TM}}$ unit pavers, and PICPs with primarily joint-driven water flow, such as Aqua Roc ${ }^{\mathrm{TM}}$ systems. PPSs are diverse, including unique designs like JW Eco-technology pavement, which eliminates runoff with a grid of open passageways, relying on the sub-base for filtration. Furthermore, PPSs vary in paver porosity (impervious or pervious) and paver material (including asphalt, clay, and plastic) and joint materials (including dirt, sand, and aggregate).

\subsection{Improving Testing Standards}

\subsubsection{ASTM International C1232-17 on Terminology}

C1232-17 Standard Terminology for Masonry offers definitions applying to "manufactured masonry units and masonry constructed with manufactured masonry units", with masonry being "a type of construction" with manufactured masonry units "laid with mortar, grout, or other methods of joining" (emphasis added) [43]. Thus, the standard rightly includes "permeable unit pavement systems", allowing for open-graded aggregate joints, and even "other openings" (e.g., open to a base), a definition consistent with Figure 4.

Ultimately, targeted standards are needed to properly address the terminology and functionality of pervious pavements. Meanwhile, additional definitions should be domiciled in C1232, such as: pervious (pavers or jointing materials allowing water flow), porous paving units (allowing water flow through the pavers), and open-patterned paving systems (contrasted with closed/interlocking-patterned paving systems). Furthermore, removing the unnecessary restriction of C1232 to "manufactured" masonry units would allow the standard to cover natural stone paver systems.

\subsubsection{ASTM International C1701/C1701M-17a and C1781/C1781M-18 on Water Infiltration}

C1781/C1781M Standard Test Method for Surface Infiltration Rate of Permeable Unit Pavement Systems is "functionally identical" to C1701/C1701M Test Method for Infiltration Rate of In Place Pervious Concrete with additional "provisions for positioning and securing the test ring to a discontinuous surface" [44]. $\mathrm{C} 1701 / \mathrm{C} 1701 \mathrm{M}$ wisely recommends repeated testing over time to track reductions in infiltration rate, as well as testing multiple locations to account for potential variations present across a continuous surface (e.g., heavy traffic areas). C1781/C1781M-18 accommodates discontinuous surfaces by making recommendations for selecting a "representative area of the pavement" (a method that is "typically within $\pm 20 \%$ of the average drainage area of the pavement as a whole"). Additionally, Appendix 
X1 offers further steps to improve the determinism of the PUPS test, based on ensuring accurate representation of the fraction of the pavement system area being inter-paver joint area.

The primary weakness in the C1781/C1781M-18 testing method is retaining C1701/1701M-17a's standardized circular infiltration ring of diameter $12^{\prime \prime} \pm 0.5^{\prime \prime}(30.5 \mathrm{~cm} \pm 1.3 \mathrm{~cm})$, despite permeable pavement systems' significantly larger horizontal flow distances and characteristic surface areas. Further consideration is warranted for the size of the unit pavers (often between 4 and 12" $(10.2-30.5 \mathrm{~cm})$ ), since the homogenization error depends on the paver/ring size ratio [50]. Furthermore, permitting non-circular grids would offer enhanced accuracy, especially if bordering were encouraged along flow-neutral paths (where flow would not normally occur across the testing boundary). To achieve reliable testing, standards should call for a testing area more an order of magnitude larger than the characteristic area of the paving system and utilize boundaries along flow-neutral paths (including non-circular shapes), without resorting to surface inundation tests. Further improvements would be to account for porous paving units by altering the calculus of Appendix $\mathrm{X} 1$ and setting targets for initial and continued infiltration rates.

\subsubsection{ASTM International C936/C936M-18, D4832-16, and C1319-17 on Properties and Inspection}

C936/C936M Standard Specification for Solid Concrete Interlocking Paving Units specifies properties of Permeable Interlocking Concrete Pavements (PICPs), including thickness, compressive strength, and other physical characteristics [51]. These quantitative specifications demonstrate precedent for setting infiltration rate "targets" as described in Section 3.2.2. Although paving unit absorption is addressed in the standard, infiltration is omitted. Effectively, C936/C936M-18 (like C1781/C1781M) excludes porous paving units without offering a separate standard for lower strength porous paving units, for which strength is especially important. Furthermore, it is unclear why non-Portland cement-based pavers are excluded. Certain practitioners employ ASTM International's D4832-16 Standard Test Method for Preparation and Testing of Controlled Low Strength Material (CSLM) Test Cylinders, though the standard is limited to materials with compressive strengths under $1200 \mathrm{psi}$ and uses test cylinders smaller than the infiltration rings of C1781/C1781M-18 [52]. A slightly more suitable option for modification is ASTM International C1319-17 Standard Specification for Concrete Grid Paving Units, since that standard has greater applicability to surface materials (instead of primarily sub-base materials), though it remains prohibitively difficult to broaden the scope to include high porosities and diverse materials. In sum, future standards should address the mechanical and hydraulic property requirements (or targets) for porous pavements and permeable pavement systems and offer clarified strength testing procedures.

\subsection{Framework for Holistic Green Design}

Within the academic literature, studies and reviews of the physical properties of different pervious pavement compositions continue to be published at an extraordinary rate $[18,46,53,54]$. As researchers explore unique components such as palm kernel shells [55], waste tire rubber [56], recycled aggregate concrete [57], and recycled plastics [53], and special applications such as overlays [58] and integrated perforated pipe pathways [59], the high volume of publications will undoubtedly continue. Since the present section focuses on offering a unique cohesive vision for pervious pavements, detailing every related research study and applying that vision to every possible application is clearly outside the present scope. The holistic framework described here explicitly connects different aspects of pavement design and describes "what ought to be" instead of "what is", extending beyond the flora and fauna to include humanity. Humanity should be connected to nature, not controlling nature or above nature, and the framework that follows illustrates that vision. 


\subsubsection{Functional Surface for Travel}

Pavements are made for travelers, so pavement designers should carefully envision the traveler's experience when selecting a pavement. It is possible for designers to match pavements to travelers so successfully that traveling brings enjoyment. Alternatively, an ineffective travel surface is, ipso facto, an insurmountable flaw. Take the example of joggers, open-celled grids (e.g., Turfstone ${ }^{\mathrm{TM}}$ ) with grass infill can offer increased exercise benefits (higher calorie burning, less joint impact) and preserve contact between the traveler and the natural environment, yet travelers may still desire a flatter surface (no "bump anxiety") and separation from impediments (e.g., mud). Certain aspects of this vision are present when traveling over FieldTurf, perhaps offering materials engineers inspiration for future biomimetic pavements or encouraging the use of resilient, cushioning, ground cover plant infills. The best designs work to conserve the traveler's experience instead of merely designing the traveler's experience, which occurs by employing the full collection of Low Impact Design (LID) fundamentals [60].

This first aspect of the framework envisions a safe and effective pervious pavement surface. For human travel, closed-grid PUPSs can only achieve suitable flatness (e.g., for Americans with Disabilities Act compliance in the U.S.) through careful selection of joint size, joint shape, and joint fill level, and compliance is impossible for certain open-grid systems [61]. Sharp corners on aggregate infill and pavers pose risks to those in wheelchairs, wearing high heels, traveling shoeless, or operating vehicles with pneumatic tires. Furthermore, regarding safety, suitable skid-resistance under various conditions (e.g., dry, wet) is essential, tempering the pursuit of flatness since traction typically increases with surface roughness (e.g., porous pavements) [62].

\subsubsection{Environmental Harmony of Appearance and Noise}

Designers should seek to maintain the visual and aural seemliness of the natural environment, promoting (not eroding) harmony. Even for those without direct contact with the pavement (i.e., bystanders, passengers), pavement designs can positively impact their interaction with the natural world. For example, PUPSs communicate their green function with their appearance by showing how runoff reduction occurs, promoting environmental consciousness [61]. More generally, pervious pavements preserve a natural appearance when they employ natural patterns and native grasses, woods, and stones. Such visual harmony is not restricted to the human perspective, successful designs also consider the perspective of the bird overhead, the rabbit in the grass, and the worm below. When all perspectives are valued, the design achieves harmony and species are brought together. For example, harmony (from the animal's perspective) is greatly enhanced by providing corridors for animal passage (without encountering traffic) that are designed to preserve existing movement patterns and sized for local wildlife species. Pervious pavements are an avenue for designers to address the need for reconciliation (repairing ecological relationships).

Road-traffic noise diminishes the experience of nature and overall quality of life in areas near high-traffic roadways, with established negative impacts on animal life in surrounding areas [63]. As an example, the noise from passenger cars traveling over porous asphalt is about $5 \mathrm{~dB}$ lower than that of traditional pavements due to increased acoustic absorption by porous pavements [64]. In this way, implementing low-noise pavement on roadways maintains peace and maximizes belonging in the environment, which supersedes the potential safety benefits of artificially loud noise (e.g., hearing a vehicle coming).

\subsubsection{Durability in Operating Environment}

Pervious pavement durability is best defined as the ability to withstand the entire collection of external factors associated with its operating environment. Wear and damage are cumulative, so numerous factors should be considered in combination with the pavement's repeated contact with users and users' vehicles noted by Xie et al. [18]. Pervious pavements are subjected to unique 
combinations of wetness, debris, freeze/thaw cycles, UV radiation, sub-grade instability and moisture, corrosive chemicals, biological organisms, and various special conditions (wildlife travel, farm equipment, fireworks, vehicle jacks, etc.). Interestingly, a holistically successful design will experience more frequent usage, demanding extra durability.

Almost a decade ago, uses of silica fume, superplasticizer, and polymer modification achieved porous concrete compressive strengths of 32-46 MPa (4640-6670 psi) [54]. For the most common applications of pervious pavements, low traffic roadways, walkways, and parking lots, several examples of decades-long durability have been documented across different types of pervious pavements $[17,46]$. As an example, a U.S. EPA study found porous asphalts to have lower freeze/thaw stress than conventional pavement, potentially leading to a doubling of service life from 15 to 30 years (in continental or polar climates) [65]. Regarding discontinuous surfaces in polar zones, certain interlocking paving systems have been shown to tolerate snow plowing equipment [61]. These temperature-dynamic climates favor pavements with low air void percentages, which tend to offer more tensile and compression strength [66]. While many published results are encouraging, the field needs generalized durability models with demonstrated accuracy across stress factors, climates, and amounts of recycled (and other eco-friendly) materials.

\subsubsection{Initial Hydraulic Performance}

The holistic vision for infiltration rate is to broadly realize positive impacts on the ecosystem and stormwater network. Research by Newman et al. confirmed that high-biodiversity can be present in and under pervious pavement systems [67], yet future refinements such as jump-starting the microbiological development in pervious pavements after installation are needed, as well as creative uses (and management) of sub-base water reservoiring. With flourishing microorganisms, organic materials clogging passageways are decomposed, sequestered oils are broken down, plants and soil-dwelling organisms are fed, and beauty and bounty proceed up the food chain.

Narrowly focusing on stormwater percolation, pervious pavements are designed to handle some percentage of a "design storm", typically above $100 \%$ to account for timewise performance decline. As context, "beginning of life" infiltration rates are frequently hundreds of inches per hour (roughly $500-2500 \mathrm{~cm} / \mathrm{hr}$ ), gradually decreasing to a few inches per hour (or tens of inches per hour) (roughly $10-200 \mathrm{~cm} / \mathrm{hr}$ ) in the presence of loose fines, and rarely dropping below that level [68]. Basing flow capacity on local weather conditions coincides with Principle \#8 of the 12 Principles of Green Engineering; namely, to design according to the functionally necessary capacity rather than using a "one size fits all" approach [69]. In most areas, pervious pavements are able to keep runoff at or below pre-development levels, retaining on site the stormwater of at least an 80th percentile local storm [11], frequently achieved by infiltration rates above $3 \mathrm{in} / \mathrm{hr}(7.5 \mathrm{~cm} / \mathrm{hr})$ [17].

\subsubsection{Maintenance of Hydraulic Performance}

Designers play an essential role in planning for sufficiently regular maintenance of the surface material, keeping the system from falling into disrepair and losing potential environmental benefits. When clogged by foreign particles such as sand, silt, clay, and organic matter, surface layers may become the dominant resistance in the flow resistance network, yet designers should also recognize that partially clogged surfaces are often capable of high infiltration rates and enhanced filtration efficacy [12]. Proper green designs should offer resiliency by using strategies such as passive failures (e.g., cracks not rendering the pavement ineffective through layering), self-healing (e.g., in-built mechanisms to repair cracks, such as epoxies or biological growth), and if necessary, ease of repair (e.g., not requiring elaborate equipment or specialized materials). Researchers assist designers in this regard by developing equipment and maintenance schedules targeting small private entities that do not possess the resources, maintenance expertise, sophisticated equipment, or maintenance routines of large government affiliated entities. 
The efficacy and cost of maintenance (traditionally vacuuming, pressure-washing, or skimming) is a common topic of investigation across pervious pavement types and pavement applications. As examples for different pavement types, Bean et al. found CGP-based system infiltration rates improved from $5 \mathrm{~cm} / \mathrm{hr}(2 \mathrm{in} / \mathrm{hr})$ to $8 \mathrm{~cm} / \mathrm{hr}(3.2 \mathrm{in} / \mathrm{hr}$ ) after maintenance [68], Cahill et al. observed porous asphalt maintaining rates of tens of inches per hour (roughly $50-225 \mathrm{~cm} / \mathrm{hr}$ ) even after long periods of under maintenance [70], and McCain and Dewoolkar found porous concrete's infiltration rate to be restored to "within 10\%" of the initial range of $572-4392 \mathrm{~cm} / \mathrm{hr}(225-1729 \mathrm{in} / \mathrm{hr})$ [71]. In the event of overloading or mismanagement, Gerrits and James demonstrated restorative benefits through skimming 10-20 mm (0.04-0.08 in.) from the top of inter-paver joints [72]. Maintenance frequencies may be as frequent as quarterly [40] or twice/yr [70] or once/yr [68]. Organizations such as the Oregon DOT have expressed concern over maintenance demands in high-traffic areas [73], for which Baladès et al.'s foundational study found infiltration rates deteriorating by approximately $40-70 \%$ within the first year, while very polluted areas experienced a first year decrease of 60-90\% [74]. Baladès et al. found that infiltration rates for residential installations decreased by about $50 \%$ by the second year after installation, whereas shopping mall parking lots were found to experience a reduction of $35 \%$ by the third year [75], suggesting modest infiltration-related maintenance demands.

\subsubsection{Pollution Sequestration and Remediation}

Pervious pavements, by definition, allow water passage, presenting designers with the opportunity to sequester or remediate the pollutants entrained. Going beyond LEED's simple goal of reducing pollutant passage [11], remediation enhances sustainability and eases end of life challenges, and some sequestration facilitates reclamation. For example, microorganisms can break down automotive lubricating oils [67] and the metals (especially heavy metals) contained in the oils can be trapped near the pavement surface for reclamation during maintenance [76]. Remediation also acknowledges the carbon dioxide conversion of the simplest grass infills and guides the use of nanotechnologies and biological materials to grow and maintain roads, creatively adapting research findings like those on mycelia [77].

As examples of filtration effectiveness, porous concretes have been shown to effectively filter out 95 percent of all suspended solids, 65 percent of all phosphorous, and virtually all metal particles [71]. Grid-type pavements and concrete interlocking pavers have also been shown to filter out any and all oils, metals, and even nitrogen from incoming infiltrated water [78]. CGPs with sand in-fill offer especially impressive nitrogen removal [79]. Furthermore, researchers are identifying the pollutants that are introduced into groundwater resulting from percolation through pervious pavement, filling information gaps for designers. Important progress towards generalized models has characterized filtration processes in terms of passageway geometry (e.g., effective void fraction, tortuosity, relative mean pore size, pore/void shape, and debris loading) and the complementary biological and mechanical mechanisms in effect.

\subsubsection{Impact of Manufacturing and Installation}

Holistic green design occurs using a closed system framework (not ignoring any inflows or outflows), accounting for that which is taken from the earth (e.g., lost resources, damaged landscapes), hazardous byproducts of production (e.g., nitrogen oxides from high temperature processes), and resource use during installation (e.g., transportation). Designers pursue LID by limiting environmental disruption on site and tracing back to the original source(s) of each material. One mode of systematized tracing is "embodied carbon" [80], which offers designers a measure of (one aspect of) the environmental impact of material production. Environmental accounting shows that the production of cement is responsible for as much as $10 \%$ of global carbon dioxide emissions, motivating innovations such as alternative clinker chemistries, carbon dioxide sequestration, and compositing with byproduct/recycling materials [15]. These innovations are particularly relevant to porous concrete since "Portland cement is the most costly constituent of concrete, both financially and environmentally", with porous concrete 
containing "more cement than does dense concrete" [12]. Environmental accounting, of course, extends beyond carbon dioxide, yet a lack of standardized emissions transparency is blocking the path forward to deploying more comprehensive metrics.

Designers may see initial costs of USD 0.50-1.00 per square foot (EUR 4.79-9.58 per square meter) for porous asphalt, USD 2.00-7.00 per square foot (EUR 19.16-67.06 per square meter) for porous concrete, and USD 5-10 per square foot (EUR 47.88-95.76 per square meter) for concrete pavers [38]. Among candidate PUPSs, "geotextile" fabrics are among the cheapest with a base cost of USD 0.70-1.00 per square foot (EUR 6.70-9.58 per square meter). Holistically, sub-bases and sub-grade preparations (including chemically modified sub-grade treatments) are comparable for most pervious pavements, and while materials tend to be $10-20 \%$ more expensive than traditional pavements, additional costs may be offset by eliminating the need for a storm water detention basin and other storm water infrastructure [38]. Furthermore, green design considers all costs and benefits, including environmental.

\subsubsection{Urban Heat Island Effect Mitigation}

A hallmark of holistic design is thorough consideration of circumstances, including the "built environment" resulting from urbanization, where pavements cover an average of $30-45 \%$ of land [81]. Urbanization can become simultaneously detrimental to humans and their environment through the heat island effect, in which pavement temperatures elevate to $120-150^{\circ} \mathrm{F}\left(48.9-65.6^{\circ} \mathrm{C}\right)$ by absorbing solar radiation through ultraviolet, visible, and infrared light [81]. Designers safeguard humans (and other life) from the discomforts and health risks of high ambient temperatures by using pavements with a high Solar Reflectance Index (SRI) (e.g., recycled aggregate mixtures [82]), yet maximizing SRI is an oversimplification lacking holistic vision. Other factors warranting consideration are: the vision for fostering environmental harmony in the surrounding area, modifying SRI through surface coatings, limiting reflectance in the visible range, preserving overnight cooling patterns, and avoiding outsized bacterial growth or thermal shock to aquatic life [13]. Green designers can effectively manage temperature and humidity by using physical measurements and simulations to tune pervious pavement SRI, evaporative cooling, water reservoiring, and material adaptivity.

\subsubsection{End of Life}

Pervious pavements should result in limited environmental impact after removal from service, in what might be holistically thought of as low impact redevelopment (minimal environmental impact of pavement removal and replacement). As with many products, the 12 Principles of Green Engineering guide designers in this context, where post-service impacts are avoided by using non-hazardous materials (Principle \#1), renewable and non-depleting materials (Principle \#12), beneficially-disposable materials or reusable/recyclable materials (Principle\#6), and accounting for the complications associated with using multi-component products (Principle \#9). Instead of considering the end of life as a final consideration, the end if life is "designed" and ranked as highly as any other green design criterion. Designers need accelerated development of "recycle-in-place" pavements, building on recent European advancements in composite recycling, allowing the on-site material to be reprocessed and reinstalled, effectively replacing itself.

\subsubsection{Sustainable or Restorative}

In the holistic view, pervious pavement project economics reflect the intentions and values of the designer, especially surrounding the creation of a design that benefits the environment (including humankind). For example, sufficient design cost allocations allow the designer to employ the full design framework to each project, ideally avoiding the use of municipally mandated pavement cross-sections. Prescribed design uniformity is especially antithetical to pervious pavement designs, which intrinsically demand sensitivity to local environmental needs, including hydrologic and biological. Going beyond the neutrality represented by sustainability triad (economic, social, and environmental sustainability) 
"bottom line" values of zero, pervious pavements offer hope for moving towards remediation (being restorative) and reconciliation (repairing ecological relationships).

\section{Discussion}

In response to the conflicting and confusing uses of porous, permeable, and pervious (the three most prominent adjectives used to describe pavements allowing water passage), this study thoroughly examines each words' linguistic origins and published uses. Ultimately, the investigation produces a novel terminological structure (Figure 4) that clearly differentiates the three adjectives within a classification hierarchy, keeping fidelity to the words' linguistic origins and accounting for trends in various types of publications. "Pervious pavements" is the overarching term for all pavements allowing water passage, due to literally meaning "through" the "road", and nicely contrasting with the well-understood "impervious". "Porous pavements" is used with continuous surface materials where hydraulic performance is dominated by the pores, which ties directly to the meaning "full of pores" and agrees with much of the published literature. "Permeable Pavement Systems (PPSs)" then compliments porous pavements by encompassing all discontinuous surface systems, allowing flow "through" infill or porous pavers as well as "around" impervious pavers. This use of PPSs agrees with a strong trend in the literature and hierarchically breaks down cleanly into Permeable Unit Paver Systems (PUPSs), which itself includes open-grid Concrete Grid Paver (CGP) systems and closed-grid Permeable Interlocking Concrete Paver (PICP) systems. Most of the lesser-known subdivisions of porous pavements and permeable pavement systems were excluded from the terminological structure in the interest of focusing on the larger picture; however, the definitions themselves and entries titled "alternatives" make clear where emerging and future pavement technologies fit in.

Issues with standards also receive examination, beginning with terminology and proceeding to formats and testing procedures. In general, ASTM International defines few terms in the field of pervious pavements, and further definitions are needed to encourage unity in research and practice. "Pervious concrete" is a case where standards should change terms ("pervious" to "porous"), moving to the preferred term from an acceptable term (in casual terms "porous" is a type of "pervious"). Substantial discussion surrounds the use of infiltration rings (or double infiltration rings) for testing the surface infiltration rate of PUPSs, with the $12 \mathrm{in}$. $(30.5 \mathrm{~cm})$ diameter ring geometry being shown to introduce homogenization errors. The noted unreliability of PUPS infiltration rate testing should be addressed by using larger testing areas with boundaries along flow-neutral pathways.

The more theoretical part of the study offers a 10-part holistic green design framework for pervious pavement design. Each aspect of the framework is explained in broad, elevated terms, offering a vision for pervious pavements that is then contextualized with examples of published results and emerging research opportunities. The framework allows practitioners and materials engineers to reimagine pervious pavements for the benefit of the environment (including humans). Primary aspects of the framework are outlined in Table 2.

With the 10-part holistic green design framework, designers are able to deduce specifications for specific pervious pavement projects, including allotting the requisite time to produce an environmentally friendly design. Designers employing a holistic vision see the interconnected collective formed by individual specifications. As an illustration of this interconnected vision, when pervious pavement designs support microbial life, microbial life remediates pollution, cleaning the atmosphere for terrestrial life, protecting earth-dwelling organisms, and enabling material reuse. Terrestrial life thrives in the area of healthy soil and air, where the bountiful earth provides food and displays immense beauty to travelers, who grow in appreciation for the natural environment and seek to restore that which has been lost. Environmental consciousness renews the use of local/natural materials, the termination of sprawling stormwater networks, the elimination of manufacturing emissions, and the appreciation for stormwater as a resource. Designers should consider the 10-part framework an interconnected web where the parts are interrelated and the whole is greater than the sum of the parts. 
Table 2. Simplified Overview of Holistic Green Design Framework for Pervious Pavements.

\begin{tabular}{|c|c|}
\hline Aspect of Framework & Description of Framework Aspect \\
\hline Functional Surface for Travel & $\begin{array}{l}\text { Pleasant travel experience. Evenness for wheelchairs/high } \\
\text { heels, offering sufficient wet/dry skid resistance, cushioning } \\
\text { jogging impact, dull edges for avoiding tire/foot punctures, } \\
\text { offering a "touch" connection surface that connects travelers } \\
\text { to nature. }\end{array}$ \\
\hline $\begin{array}{l}\text { Environmental Harmony of } \\
\text { Appearance and Noise }\end{array}$ & $\begin{array}{c}\text { Preference for natural materials, shapes, patterns, and } \\
\text { lifeforms. Environment (e.g., plants, wildlife) flourishes } \\
\text { when needs are met; perspective of plants, birds, rabbits, } \\
\text { worms all considered. Prevention of excessive road noise } \\
\text { from intended modes of travel. }\end{array}$ \\
\hline $\begin{array}{l}\text { Durability in Operating } \\
\text { Environment }\end{array}$ & $\begin{array}{l}\text { Move lifespans from decades into centuries. Strength to } \\
\text { support loads and retain passageways, UV resistance, } \\
\text { freeze/thaw resistance, hardness for long wear life and } \\
\text { abrasion resistance, impact resistance for drops, crashes, and } \\
\text { rapid acceleration/deceleration, and chemical compatibility } \\
\text { for deicing and leaks/spills. }\end{array}$ \\
\hline Initial Hydraulic Performance & $\begin{array}{l}\text { Hydraulic conductivity to support local "design storms", } \\
\text { retention of water for irrigation. Driven by local hydraulic } \\
\text { needs and goals, sub-grade characteristics (e.g., clay helps } \\
\text { reservoiring). }\end{array}$ \\
\hline $\begin{array}{l}\text { Maintenance of Hydraulic } \\
\text { Performance }\end{array}$ & $\begin{array}{l}\text { Effective and affordable maintenance, passive failures, } \\
\text { infrequent maintenance requirements with accessible } \\
\text { machinery, recovery of high percentage of initial hydraulic } \\
\text { conductivity. }\end{array}$ \\
\hline $\begin{array}{l}\text { Pollution Sequestration and } \\
\text { Remediation }\end{array}$ & $\begin{array}{l}\text { Effective capture of suspended solids, retention of road } \\
\text { runoff pollution such as lubricating oils, remediation through } \\
\text { maintenance or other/biological reclamation processes. } \\
\text { Consider local pollution types/levels and water needs. }\end{array}$ \\
\hline $\begin{array}{l}\text { Impact of Manufacturing and } \\
\text { Installation }\end{array}$ & $\begin{array}{l}\text { Low impact manufacturing to produce low cost materials } \\
\text { with easy installation. Consider locally available materials, } \\
\text { soil conditions, and technologies. }\end{array}$ \\
\hline $\begin{array}{l}\text { Urban Heat Island Effect } \\
\text { Mitigation }\end{array}$ & $\begin{array}{c}\text { High solar reflectance index and enabling evaporative } \\
\text { cooling. Consider local environment holistically, especially } \\
\text { population density and weather. }\end{array}$ \\
\hline End of Life & $\begin{array}{l}\text { Prefer plentiful (non-depleting), non-toxic, separable, and } \\
\text { reusable or recyclable materials. Move to "repair in place". }\end{array}$ \\
\hline Sustainable or Restorative & $\begin{array}{l}\text { Satisfy sustainability triad and look for ways to restore } \\
\text { nature, improve livability for wildlife, improve beauty, } \\
\text { facilitate social interaction, decrease pollution. }\end{array}$ \\
\hline
\end{tabular}

Pervious pavements, though, face interconnection challenges in withstanding repeated loadings while containing passageways for water, maintaining open passageways in the presence of natural and traveler-introduced particles, allowing safe and comfortable travel over surface discontinuities, receiving timely maintenance from uninitiated owners with limited equipment, and achieving reuse and recycling without existing infrastructure.

Designers eagerly await the advancement of research through the generalization phase with models extracted from multi-parameter studies, as well as multi-disciplinary studies focused on the impacts of pervious pavements on humans and other lifeforms. When the designer employs the holistic framework with the proper sensitivity, they act as a faithful steward of the environment, making major advances in pervious pavements through low impact development. 
Author Contributions: The authors collaboratively conceptualized the research effort and worked together on the investigation and methodology. C.H. initially drafted the manufacturing and pollutant sequestration results, O.O. initially drafted the green design perspective results, and H.T. initially drafted the terminology and standards results. C.E.S.III provided resources, administration, review, editing, and revisions. All authors have read and agreed to the published version of the manuscript.

Funding: This research received no external funding.

Conflicts of Interest: The authors declare no conflict of interest.

\section{References}

1. Ghafoori, N.; Dutta, S. Laboratory Investigation of Compacted No-Fines Concrete for Paving Materials. J. Mater. Civ. Eng. 1995, 7, 183-191. [CrossRef]

2. Thelen, E.; Howe, L.F. Porous Pavement: Including the Principles of Development and a Porous Pavement Design Manual; The Franklin Institute Press: Philadelphia, PA, USA, 1978.

3. U.S. Green Building Council. About (USGBC). Available online: https://www.usgbc.org/about/brand (accessed on 29 June 2020).

4. Jacob Kriss-U.S. Green Building Council. Narrative of the history of LEED's development. In Proceedings of the Greenbuild International Conference and Expo, Philadelphia, PA, USA, 20-22 November 2013.

5. U.S. Green Building Council. LEED 2009 (LEED v3); Green Building Council: Washington, DC, USA, 2009.

6. U.S. Green Building Council. LEED 2009 (LEED v3). Addenda 100001374. Available online: https: //www.usgbc.org/leedaddenda/100001374 (accessed on 11 September 2020).

7. U.S. Environmental Protection Agency-Office of Water. Low Impact Development (LID): A Literature Review; U.S. Environmental Protection Agency: Washington, DC, USA, 2000.

8. 110th United States Congress. Energy Independence and Security Act of 2007; U.S. Government Publishing Office (GPO): Washington, DC, USA, 2007.

9. U.S. Environmental Protection Agency. Technical Guidance on Implementing the Stormwater Runoff Requirements for Federal Projects under Section 438 of the Energy Independence and Security Act; Office of Water: Washington, DC, USA, 2009.

10. Ashley, E. Using Pervious Concrete to Achieve LEED Points; Concrete Infocus: Alexandria, VA, USA, 2008.

11. United States Green Building Council. LEED v4.1. Available online: https://www.usgbc.org/leed/v41 (accessed on 18 May 2020).

12. Ferguson, B.K. Porous Pavements; CRC Press: Boca Raton, FL, USA, 2005.

13. U.S. Environmental Protection Agency. Reducing Urban Heat Islands: Compendium of Strategies-Chapter 5: Cool Pavements.; 2012. Available online: https://www.epa.gov/heat-islands/heat-island-compendium (accessed on 27 May 2020).

14. Zanoni, L. The Benefits of Using Porous Asphalt Pavement in Comparison with Other Forms of Pervious Pavements; University of Illinois at Chicago: Chicago, IL, USA, 2019.

15. Siegel, R.P. Cutting the carbon from concrete. Mech. Eng. 2020, 142, 38-43. [CrossRef]

16. U.S. Environmental Protection Agency. Technical Guidance on Implementing the Stormwater Runoff Requirements for Federal Projects. December 2009. Available online: https://www.epa.gov/sites/production/ files/2015-08/documents/epa_swm_guidance.pdf (accessed on 29 May 2020).

17. Hunt, W.F.; Collins, K.A. Permeable Pavement: Research Update and Design Implications; North Carolina Cooperative Extension Service: Raleigh, NC, USA, 2006.

18. Xie, N.; Akin, M.; Shi, X. Permeable concrete pavements: A review of environmental benefits and durability. J. Clean. Prod. 2019, 210, 1605-1621. [CrossRef]

19. Brown, R.A.; Borst, M. Evaluation of surface infiltration testing procedures in permeable pavement systems. J. Environ. Eng. 2014, 140, 04014001. [CrossRef]

20. West, D.; Kaye, N.B.; Putman, B.J.; Clark, R. Quantifying the non-linear hydraulic behavior of pervious concrete. J. Test Eval. 2016, 44, 20150054. [CrossRef]

21. Ullman, D. The Mechanical Design Process; McGraw-Hill: New York, NY, USA, 2017.

22. Budynas, R.G.; Nisbett, J.K. Shigley's Mechanical Engineering Design; McGraw-Hill: New York, NY, USA, 2016.

23. Mihelcic, J.R.; Zimmerman, J.B. Environmental Engineering: Fundamentals, Sustainability, Design; John Wiley \& Sons: New York, NY, USA, 2014. 
24. Ashby, M.F. Materials Selection in Mechanical Design; Butterworth-Heinemann: Oxford, UK, 2017.

25. Callister, W.D., Jr.; Rethwisch, D.G. Materials Science and Engineering: An Introduction; John Wiley \& Sons: New York, NY, USA, 2013.

26. Schulze, P.C.; Cairns, J., Jr.; Holling, C.; Borton, B.G.; Herman, R.; Costanza, R.; Karr, J.R. Engineering Within Ecological Constraints; National Academy Press: Washington, DC, USA, 1996.

27. Gunn, A.S.; Vesilind, P.A. Environmental Ethics for Engineers; Lewis Publishers: Chelsea, MI, USA, 1986.

28. Intergovernmental Panel on Climate Change. Global Warming of 1.5 degrees Celsius; Cambridge University Press: Cambridge, UK, 2018.

29. Pope Francis, I. Laudato Si': On Care for Our Common Home; Libreria Editrice Vaticana: Vatican City, Vatican, 2015.

30. Scholz, M.; Grabowiecki, P. Review of permeable pavement systems. Build Environ. 2007, 42, 3830-3836. [CrossRef]

31. Jayasuriya, N.; Kadrupokune, N. Comparative Performance of Permeable and Porous Pavements. In Proceedings of the International Conference on Sustainable Built Environment, Kandy, Sri Lanka, 13-14 December 2010.

32. Online Etymology Dictionary (Douglas Harper). Porous. Available online: https://www.etymonline.com/ word/porous (accessed on 25 May 2020).

33. Houghton Mifflin Harcourt Publishing Company. American Heritage Dictionary of the English Language; Houghton Mifflin Harcourt Publishing Company: Boston, MA, USA, 2016.

34. Online Etymology Dictionary (Douglas Harper). Permeable. Available online: https://www.etymonline.com/ word/permeable (accessed on 25 May 2020).

35. Online Etymology Dictionary (Douglas Harper). Pervious. Available online: https://www.etymonline.com/ word/pervious (accessed on 25 May 2020).

36. Hunt, W.F.; Szpir, L.L. Permeable Pavements, Green Roofs, and Cisterns; North Carolina Cooperative Extension Service: Raleigh, NC, USA, 2006.

37. North Carolina Department of Environmental Quality. Stormwater Injection. Available online: https://deq.nc.gov/about/divisions/water-resources/water-resources-permits/wastewater-branch/ ground-water-protection/stormwater-injection (accessed on 23 May 2020).

38. CTC \& Associates LLC. Comparison of Permeable Pavement Types: Hydrology, Design, Installation, Maintenance and Cost; Wisconsin Department of Transportation: Madison, WI, USA, 2012.

39. State of New Jersey Department of Environmental Protection. New Jersey Stormwater Best Management Practices Manual (Chapter 9.7 Standard for Pervious Paving Systems); State of New Jersey Department of Environmental Protection: Trenton, NJ, USA, 2004.

40. City of Duluth. Pervious Pavements. Lake Superior Streams: Community Partnerships for Understanding Water Quality and Stormwater Impacts and the Head of the Great Lakes, 2011. Available online: https: //www.lakesuperiorstreams.org/stormwater/toolkit/paving.html (accessed on 23 May 2020).

41. Selbig, W.R.; Buer, N. Hydraulic, Water-Quality, and Temperature Performance of Three Types of Permeable Pavemet under High Sediment Loading Conditions; U.S. Geological Survey-U.S. Department of the Interior: Reston, VA, USA, 2018.

42. Permeable Pavements Task Committee. Permeable Pavements; American Society of Civil Engineers: Reston, VA, USA, 2015.

43. ASTM International. Standard Terminology for Masonry (C1232-17); ASTM International: West Conshohocken, PA, USA, 2017.

44. ASTM International. Standard Test Method for Surface Infiltration Rate of Permeable Unit Pavement Systems (C1781/C1781M-18); ASTM International: West Conshohocken, PA, USA, 2018.

45. ASTM International. Test Method for Infiltration Rate of in Place Pervious Concrete (C1701/C1701M-17); ASTM International: West Conshohocken, PA, USA, 2017.

46. Chen, L.-M.; Chen, J.-W.; Chen, T.-H.; Lecher, T.; Davidson, P.C. Measurement of permeability and comparison of pavements. Water 2019, 11, 444. [CrossRef]

47. Li, H.; Kayahanian, M.; Harvey, J.T. Comparative field permeability measurement of permeable pavements using ASTM C1701 and NCAT permeameter methods. J. Environ. Manag. 2013, 118, 144-152. [CrossRef]

48. Pantsi, C.; Wright, G.B.; Alsubih, M. Permeable Pavement Systems: State of the Art. In Proceedings of the ICUD Conference, Prague, Czech Republic, 10-15 September 2017. 
49. Alsubih, M. Understanding the Hydrological Performance of Permeable Pavement; Heriot-Watt University: Edinburgh, UK, 2016.

50. Konstandopoulos, A.G.; Kostoglou, M.; Housiada, P. Spatial non-uniformities in diesel particulate trap regeneration. SAE Tech. Pap. Ser. 2001. [CrossRef]

51. ASTM International. Standard Specification for Solid Concrete Interlocking Paving Units (C936/C936M); ASTM International: West Conshohocken, PA, USA, 2018.

52. ASTM International. Standard Test Method for Preparation and Testing of Controlled Low Strength Material (CLSM) Test Cylinders (D4832-16); ASTM International: West Conshohocken, PA, USA, 2016.

53. ASTM International. Standard Specification for Concrete Grid Paving Units (C1319-17); ASTM International: West Conshohocken, PA, USA, 2017.

54. Dhanagar, G.S.; Kumbar, P.D. Strength and durability properties of cncrete with recycled plastic aggregate: A review. Int. J. Innov. Res. Technol. 2019, 6, 271-275.

55. Chen, Y.; Wang, K.; Wang, X.; Zhou, W. Strength, fracture and fatigue of pervious concrete. Constr. Build. Mater. 2013, 42, 97-104. [CrossRef]

56. Khankhaje, E.; Salim, M.R.; Mirza, J.; Hussin, M.W.; Rafieizonooz, M. Properties of sustainable lightweight pervious concrete containing oil palm kernel shell as coarse aggregate. Constr. Build. Mater. 2016, 126, 1054-1065. [CrossRef]

57. Thomas, B.S.; Gupta, R.C. A Comprehensive Review on the Applications of Waste Tire Rubber in Cement Concrete. Renew. Sustain. Energy Rev. 2016, 54, 1323-1333. [CrossRef]

58. Volz, J.S.; Khayat, K.H.; Arezoumandi, M.; Drury, J.; Sadati, S.; Steele, S. A Recycled Concrete Aggregate (RCA) for Infrastructure Elements (NUTC R312); National University Transportation Center at Missouri University of Science and Technology: Rolla, MO, USA, 2014.

59. Kevern, J.T.; Schaefer, V.R.; Wang, K. Mixture proportion development and performance evaluation of pervious concrete for overlay applications. ACI Mater. J. 2011, 108, 439-448.

60. Mounika, P.; Srinivas, K. Mechanical Properties of no Fines Concrete for Pathways. Int. J. Eng. Technol. 2018, 4, 68-81.

61. Davis, A.P. Green engineering: Promote low (impact development). Environ. Sci. Technol. 2005, 39, 338A-344A. [CrossRef]

62. Interlocking Concrete Pavement Institute. A Comparison Guide to Porous Asphalt and Pervious Concrete. 2016. Available online: https://www.icpi.org/sites/default/files/PICP\%20Comparison $\% 20$ brochure $\% 20$ Final\% 202016.pdf (accessed on 27 May 2020).

63. Tang, T.; Anupam, K.; Kasbergen, C.; Scarpas, A.; Erkens, S. A finite element study of rain intensity on skid resistance. Constr. Build. Mater. 2019, 220,464-475. [CrossRef]

64. Parris, K.M. Chapter 16: Ecological Impacts of Road Noise and Options for Mitigation; Clean Air and Urbal Landscapes Hub: Parkville, Victoria, Australia, 2020.

65. Bichajlo, L.; Kolodziej, K. Porous asphalt pavement for traffic noise reduction and pavement dewatering-The pollution problem. In Proceedings of the E3S Web of Conferences-Infraeko, Krakow, Poland, 7-8 June 2018.

66. U.S. Environmental Protection Agency. Porous Asphalt Pavement; National Pollutant Discharge Elimination System of the U.S. EPA: Washington, DC, USA, 2009.

67. Chai, C.; Cheng, Y.-C.; Zhang, Y.; Zhu, B. Experimental study on the performance decay of permeable asphalt mixture in seasonally frozen regions under freeze-thaw cycles. Sustainability 2020, 12, 2966. [CrossRef]

68. Newman, A.P.; Coupe, S.J.; Puehmeier, T.; Morgan, J.A.; Henderson, J.; Pratt, C.J. Microbial ecology of oil degrading porous pavement structures. In Proceedings of the Global Solutions for Urban Drainage/ICUD, Portland, OR, USA, 8-13 September 2002.

69. Bean, E.Z.; Hunt, W.F.; Bidelspach, D.A. Study on the Surface Infiltration Rate of Permeable Pavements. In Proceedings of the American Society of Civil Engineers-World Water Congress 2004, Salt Lake City, UT, USA, 19-24 September 2004.

70. Anastas, P.T.; Zimmerman, J.B. Design through the 12 principles of green engineering. Environ. Sci. Technol. 2003, 37, 5349-5353. [CrossRef]

71. Cahill, M.; Godwin, D.C.; Sowles, M. Porous Pavement: Low Impact Development Fact Sheet; Oregon State Unviersity, Oregon Sea Grant: Corvallis, OR, USA, 2011.

72. McCain, G.N.; Dewoolkar, M.M. An Investigation into Porous Concrete Pavements for Northern Communities; University of Vermont \& Vermont Agency of Transportation: Burlington, VT, USA, 2010. 
73. Gerrits, C.; James, W. Restoration of Infiltration Capacity of Permeable Pavers; University of Guelph: Guelph, ON, Canada, 1993.

74. Minesota Pollution Control Agency. Minnesota Stormwater Manual. 2018. Available online: https://stormwater.pca.state.mn.us/index.php?title=Operation_and_maintenance_of_permeable_ pavement (accessed on 28 May 2020).

75. Oregon Department of Transportation. Pavement Design Guide; Oregon Department of Transportation: Salem, OR, USA, 2019.

76. Balades, J.D.; Legret, M.; Madiec, H. Permeable pavements: Pollution management tools. Water Sci. Technol. 1995, 32, 49-56. [CrossRef]

77. Colandini, V.; Legret, M.; Brosseaud, Y.; Balades, J.D. Metallic pollution in clogging materials of urban porous pavements. Water Sci. Technol. 1995, 32, 57-62. [CrossRef]

78. Jakubiak, M.; Giska, I.; Asztemborska, M. Bioaccumulation and biosorption of inorganic nanoparticles: factors affecting the efficiency of nanoparticle mycoextraction by liquid-grown mycelia of pleurotis eryngii and trametes versicolor. Mycol. Prog. 2014, 13, 525-532. [CrossRef]

79. Brattebo, B.O.; Booth, D.B. Long-term stormwater quantity and quality performance of permeable pavement systems. Water Res. 2003, 37, 4369-4376. [CrossRef]

80. Barrett, M.E. Performance, cost, and maintenance requirements of Austin sand filters. J. Water Resour. Plan. Manag. 2003, 129, 234-242. [CrossRef]

81. Building Products \& Materials Today. Materials and embodied carbon. Eng. News Rec. 2019, 48. Available online: http://digitaladmin.bnpmedia.com/publication/?m=38305\&i=583640\&p=2 (accessed on 18 May 2020).

82. Gaedicke, C.; Marines, A.; Mata, L.; Miankodila, F. Effect of Recycled Materials and Compaction Methods on the Mechanical Properties and Solar Reflectance Index of Pervious Concrete. Revista Ingeniería de Construcción 2015, 30, 159-167. [CrossRef]

(C) 2020 by the authors. Licensee MDPI, Basel, Switzerland. This article is an open access article distributed under the terms and conditions of the Creative Commons Attribution (CC BY) license (http://creativecommons.org/licenses/by/4.0/). 